\title{
Investigation of the effect of uncertain growth kinetics on a CFD based model for the growth of S. cerevisiae in an industrial bioreactor
}

Wright, Mathias Risager; Bach, Christian; Gernaey, Krist V.; Krühne, Ulrich

Published in:

Chemical Engineering Research and Design

Link to article, DOI:

10.1016/j.cherd.2018.09.040

Publication date:

2018

Document Version

Peer reviewed version

Link back to DTU Orbit

Citation (APA):

Wright, M. R., Bach, C., Gernaey, K. V., \& Krühne, U. (2018). Investigation of the effect of uncertain growth kinetics on a CFD based model for the growth of S. cerevisiae in an industrial bioreactor. Chemical Engineering Research and Design, 140,12-22. https://doi.org/10.1016/j.cherd.2018.09.040

\section{General rights}

Copyright and moral rights for the publications made accessible in the public portal are retained by the authors and/or other copyright owners and it is a condition of accessing publications that users recognise and abide by the legal requirements associated with these rights.

- Users may download and print one copy of any publication from the public portal for the purpose of private study or research.

- You may not further distribute the material or use it for any profit-making activity or commercial gain

- You may freely distribute the URL identifying the publication in the public portal 


\section{Accepted Manuscript}

Title: Investigation of the effect of uncertain growth kinetics on a CFD based model for the growth of $S$. cerevisiae in an industrial bioreactor

Author: Mathias R. Wright Christian Bach Krist V. Gernaey Ulrich Krühne

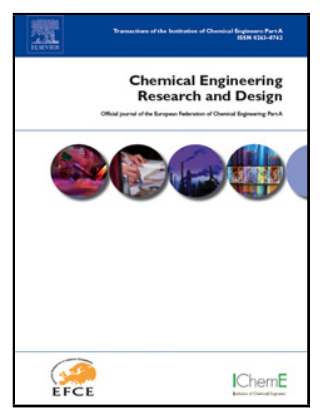

PII: S0263-8762(18)30518-5

DOI: https://doi.org/doi:10.1016/j.cherd.2018.09.040

Reference: CHERD 3368

To appear in:

Received date: $\quad$ 7-2-2018

Revised date: $\quad 18-9-2018$

Accepted date: $\quad$ 28-9-2018

Please cite this article as: Mathias R. Wright, Christian Bach, Krist V. Gernaey, Ulrich Krddotuhne, Investigation of the effect of uncertain growth kinetics on a CFD based model for the growth of $S$. cerevisiae in an industrial bioreactor, <![CDATA[Chemical Engineering Research and Design]]> (2018), https://doi.org/10.1016/j.cherd.2018.09.040

This is a PDF file of an unedited manuscript that has been accepted for publication. As a service to our customers we are providing this early version of the manuscript. The manuscript will undergo copyediting, typesetting, and review of the resulting proof before it is published in its final form. Please note that during the production process errors may be discovered which could affect the content, and all legal disclaimers that apply to the journal pertain. 
- $\quad$ CFD give opportunities, which cannot be achieved with simulations for ideal mixing.

- CFD a tool to investigate substrate gradient in industrial bioreactors.

- CFD gives an insight on the effect of strain improvements on the performance of a fed-batch 


\title{
Investigation of the effect of uncertain growth kinetics on a CFD based model for the growth of $S$. cerevisiae in an industrial bioreactor
}

\author{
Mathias R. Wright, Christian Bach, Krist V. Gernaey \& Ulrich Krühne \\ Process and Systems Engineering Centre (PROSYS), Department of Chemical and Biochem- \\ ical Engineering, Technical University of Denmark, 2800 Lyngby, Denmark
}

\begin{abstract}
The knowledge of the effect of uncertainties on kinetic parameters is fundamental, when a model is used to improve the performance of an industrial bioreactor. In this work a $100 \mathrm{~m}^{3}$ industrial bioreactor operating as a fed-batch is simulated by computational fluid dynamic (CFD) methods to investigate the effects of varying kinetics describing the growth of S. cerevisiae. The results of the simulation show that the kinetic parameters used to describe the anaerobic metabolic state have the largest influence on the glucose distribution causing a maximum deviation of $25 \%$ of the glucose profile corresponding to the base case. The uncertainties of the parameters describing aerobic metabolism affect the glucose with $2 \%$ to $5 \%$. The sensitivity of the kinetics is also investigated for four different volumes of the bioreactor operating as a fed-batch. The uncertainty of the kinetics has the largest impact at the beginning of the process, where the mixing time is relatively low and a small impact is found at the end where the mixing time is high. Finally, the influence of a varying yield coefficient on the development of the cell concentration is investigated. Only a small deviation in the cell concentration is found. However, by comparing the CFD simulation with a simulation where ideal mixing is assumed, a deviation of the biomass concentration of approximately $10 \mathrm{~g} / \mathrm{L}$ or $33 \%$ was predicted for the final volume. This work illustrates the possibility to evaluate the effect of variations in kinetic parameters using CFD, and gives an insight on the effect of potential strain improvements on the performance of a fed-batch process.
\end{abstract}




\section{Introduction}

Saccharomyces cerevisiae is widely used in industry, for applications that range from the production of beer to the production of pharmaceuticals [1]. S. cerevisiae is often cultivated in large stirred bioreactors, which are aerated. In these reactors gradients of substrates are likely to occur. Substrate gradients have been reported for several organisms in large reactors. Bylund et al. [2] observed a concentration of $2000 \mathrm{mg} / \mathrm{L}$ glucose close to the feed point of a 12 $m^{3}$ reactor with Escherichia coli. Far away from the feed point, glucose concentrations as low as $2 \mathrm{mg} / \mathrm{L}$ were observed. Furthermore, a yield loss of $20 \%$ was observed when the large-scale reactor was compared to a laboratory-scale reactor. They suggested that the yield loss was caused by overflow metabolism in substrate-rich zones and/or by anaerobic fermentation in oxygen-limited zones. This was confirmed by Larsson et al. [3] who showed that glucose gradients in a $30 \mathrm{~m}^{3}$ reactor led to the formation of undesired by-products for S. cerevisiae, which resulted in a decrease in biomass yield.

It is extremely difficult to collect good experimental data on gradients in large scale bioreactors, for example due to concerns about maintaining sterile conditions in the reactor. Commonly used methods to investigate and predict gradients in a bioreactor rely on computational models, in particular Computational Fluid Dynamics (CFD). CFD has been used to investigate and optimize bioreactors. Several studies have focused on the gas-liquid mixing. For instance, CFD was used to investigate the gas-liquid flow and power consumption in a dual Rushton turbine stirred tank with volume of $100 \mathrm{~L}[4,5]$. Furthermore, CFD has been used to predict the gas transfer coefficient $k_{L} a$ for a stirred tank with a volume of respectively 150-350 L and $80 \mathrm{~L}[6,7]$.

CFD simulations also have the potential to describe the formation of substrate gradients by combining flow simulation with kinetics of microorganisms. Haringa et al. [8] simulated the varying substrate concentrations to which Penicilium chysogenum is exposed to in an industrial bioreactor. They found that $57 \%$ of the vessel was depleted of substrate. Furthermore, Lapin et al. [9] simulated the glucose gradients to which E. coli organisms are exposed to in a $900 \mathrm{~L}$ bioreactor. They found high glucose concentrations at the top close to the feed point and glucose concentrations close to zero at the bottom of the reactor.

Several studies have also combined gas-liquid simulations with a kinetic model for the growth

Page 2 of 33

Page 3 of 29 
of microorganisms. For instance, Elgotbi et al. [10] simulated the behavior of Aspergillus niger in a $5 \mathrm{~L}$ bioreactor operating as a batch. In the study, gas-liquid simulations and the kinetics of Aspergillus niger were combined to investigate the production of gluconic acid. Morchain et al. [11] combined gas-liquid flow with a population balance model for the cells to investigate the formation of substrate gradients in a $70 \mathrm{~m}^{3}$ bioreactor with reasonable results. Common for the studies reported in the literature, when combining CFD with a kinetic model is that the effect of uncertainties on the parameters of the kinetic model is usually not considered. For instance, a deviation of $5 \%$ on the yield coefficient of biomass on glucose has been reported [12]. It is unknown how these uncertainties would affect a CFD-based model for a production size bioreactor. Furthermore, most studies do not investigate an entire production process using CFD, but only consider a snapshot of the process, for example only considering a situation where the tank is completely filled. The latter is only the case for a small period of time in case of a fed-batch process, an operating mode which is very popular in industrial fermentation.

\subsection{Purpose of paper}

In view of the above the main focus in this work is to investigate the robustness of a CFD-based kinetic model, which is used to describe the growth of $S$. cerevisiae in an industrial bioreactor with a maximum capacity of $100 \mathrm{~m}^{3}$. Furthermore, it will be investigated how the variation in the kinetic parameters affects the performance of the fed-batch operated bioreactor.

\section{Materials and methods}

\subsection{Reactor geometry}

The simulated bioreactor had a volume of $100 \mathrm{~m}^{3}$ and contained four baffles, 23 cooling coils and four Rushton turbines with six blades each. The dimensions of the reactor can be seen in Table 1, and an illustration of the reactor is shown in Figure 1. The cooling coils were simplified so they were all oriented in parallel, whereas the cooling coil in the real system is one long coil. All simulations were performed with a constant stirrer speed of $69 \mathrm{rpm}$. The constant stirrer speed was chosen in order to achieve a constant power input of approximately 
$1-2 \mathrm{KW} / \mathrm{m}^{3}$ which is typical for industrial bioreactors [13].

Table 1: Dimensions of the reactor used for simulations.

\begin{tabular}{ccl}
\hline Symbol & Dimension & Description \\
\hline $\mathrm{H}$ & $10.5 \mathrm{~m}$ & Reactor height \\
$\mathrm{T}$ & $1 / 3 \mathrm{H}$ & Reactor diameter \\
$\mathrm{d}$ & $2 / 5 \mathrm{~T}$ & Impeller diameter \\
$\mathrm{C}$ & $0.58 \mathrm{~T}$ & Impeller clearance \\
$\mathrm{B}$ & $1 / 10 \mathrm{~T}$ & Baffle width \\
\hline
\end{tabular}
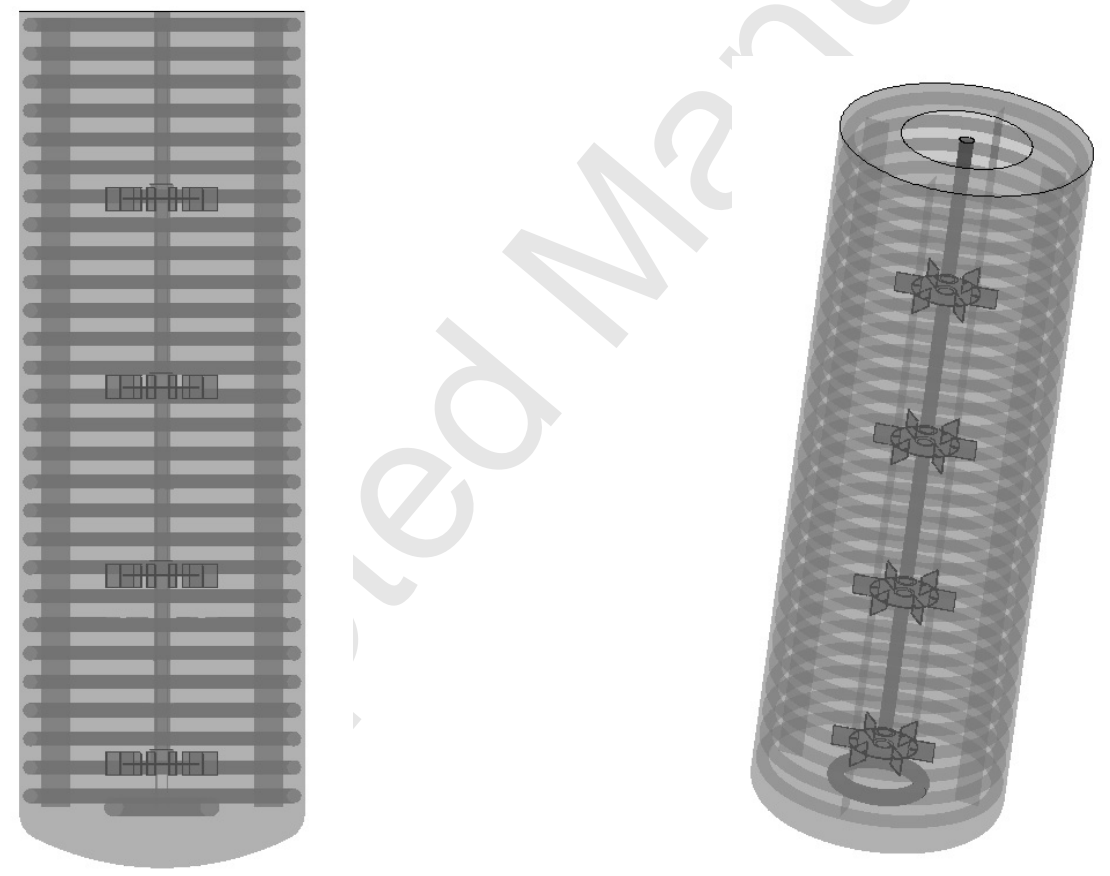

(a) Cross-sectional area of the reactor geome- (b) Three-dimensional drawing of the reactor try. geometry.

Figure 1: Geometry of the simulated reactor. The Rushton turbines and the sparger are located in the rotating domain. The baffles and coils are located in the stationary domain. 


\subsection{Simulation setup}

The CFD simulations were performed using ANSYS CFX 17. The reactor was divided into two domains: An outer stationary domain and an inner rotating domain. A structured hexahedral mesh was used for both domains. The mesh was constructed so that the mesh density (elements/volume) is highest close to important regions such as walls or cooling coils. A mesh sensitivity study was made and can be found in the supplementary material. The inner domain was defined as a rotating domain with a rotational speed of $69 \mathrm{rpm}$. The standard RANS k- $\varepsilon$ model was used to model the turbulence. All walls were defined as no-slip walls, apart from the top which was defined as a free-slip wall. Simulation of the flow was performed by solving the mass conservation equation and the momentum equation, which can be found in the supplementary material.

Only a one-phase simulation of the liquid phase was performed, where oxygen was represented as dissolved oxygen. The dissolved oxygen was defined as an additional variable present in the liquid phase. Despite the expected impact on the results of the mixing and the distribution of oxygen in the reactor, this simplification was made to shorten the simulation time in order to enable the investigation of the sensitivity of the model prediction to changes in the kinetic parameters. A description of how the oxygen transfer from gas to the liquid phase was modelled can be found in Section 2.4.1. The assumption related to one-phase simulation is discussed in Section 3.3. Just like oxygen, glucose was defined as additional variable present in the liquid phase. It was assumed that all fluid components are mixed at the molecular level, that they share the same mean velocity and that mass transfer takes place by convection and diffusion.

Since the particle Stokes number associated with the microorganisms was small, it was assumed that microorganisms would behave like a tracer substance in the continuous phase [14]. The microorganisms were therefore represented through their concentration in the liquid phase. The growth of microorganisms is relatively slow compared to e.g. the consumption of glucose and therefore the cell concentration is generally not expected to form gradients $[3,15]$. Thus, the microorganism concentration was assumed to be constant throughout the

entire reactor. The sensitivity of the kinetic model was investigated by varying the following model parameters: the half-saturation constant, the yield coefficient and the maximum spe- 
cific growth rate. Further information about how the varying kinetics that are considered in the evaluation can be found in Section 2.5.

\subsection{Metabolism of $S$. cerevisiae}

The growth of $S$. cerevisiae is well known and can generally be described by three major metabolic pathways, depending on the availability of glucose and oxygen as shown in Equations 1-3.

In the presence of oxygen, glucose will be consumed by aerobic respiration. The by-products of this reaction are carbon dioxide and water [16]. The reaction is shown in Equation 1, where $Y_{s i}$ represents the yield coefficient of compound $i$ on glucose.

$$
\mathrm{C}_{6} \mathrm{H}_{12} \mathrm{O}_{6}+Y_{s o 1} \mathrm{O}_{2} \rightarrow Y_{s x 1} \mathrm{X}+Y_{s c o 1} \mathrm{CO}_{2}+Y_{s H_{2} O 1} \mathrm{H}_{2} \mathrm{O}
$$

If $S$. cerevisiae grows in an environment with no oxygen, it shifts its metabolism from aerobic respiration to anaerobic fermentation. Without oxygen, glucose cannot be converted into carbon dioxide and water. Instead, it is converted into ethanol, as shown in Equation 2 [17].

$$
\mathrm{C}_{6} \mathrm{H}_{12} \mathrm{O}_{6} \rightarrow Y_{s x 2} \mathrm{X}+Y_{s p 2} \mathrm{C}_{2} \mathrm{H}_{6} \mathrm{O}+Y_{s c o 2} \mathrm{CO}_{2}
$$

At high substrate concentrations, $S$. cerevisiae can also produce ethanol under aerobic conditions, which is called the Crabtree effect or overflow metabolism [18]. The substrate is under such conditions converted according to a mix of aerobic respiration and anaerobic fermentation.

$$
\mathrm{C}_{6} \mathrm{H}_{12} \mathrm{O}_{6}+\mathrm{Y}_{s o 3} \mathrm{O}_{2} \rightarrow \mathrm{Y}_{s x 3} \mathrm{X}+\mathrm{Y}_{\mathrm{sco} 3} \mathrm{CO}_{2}+\mathrm{Y}_{s \mathrm{H}_{2} \mathrm{O} 3} \mathrm{H}_{2} \mathrm{O}+\mathrm{Y}_{s p 3} \mathrm{C}_{2} \mathrm{H}_{6} \mathrm{O}
$$

The yield coefficients depend on the yeast strain, the media composition and the conditions to which the yeast cells are exposed. For instance, Hoek et al. [19] found a yield coefficient for aerobic metabolism $\left(Y_{s x 1}\right)$ at $0.46 \mathrm{~g} / \mathrm{g}$, whereas Postma et al. [12] measured it to be 0.51 $\mathrm{g} / \mathrm{g}$ for a different yeast strain. 


\subsection{Kinetic model}

A kinetic model based on classical Monod kinetics was used to describe the growth rate, where the growth depends on one limiting substrate.

$$
\mu=\mu_{\max } \frac{C_{s}}{C_{s}+K_{s}}
$$

where $\mu$ is the specific growth rate, $\mu_{\max }$ is the maximum specific growth rate, $C_{s}$ is the substrate concentration of the limiting substrate, and $K_{s}$ is the half-saturation concentration. From the growth rate, an equation for the glucose uptake rate can be formulated:

$$
q_{s}=\frac{\mu \cdot C_{x}}{Y_{s x}}
$$

where $q_{s}$ is the glucose uptake rate, $C_{x}$ is the cell concentration, and $Y_{s x}$ is the yield coefficient. From the glucose consumption rate, a general mass balance for glucose can be formulated and was solved in the simulations.

$$
\frac{\partial C_{s}}{\partial t}+\nabla\left(C_{s} U\right)+q_{s}=0
$$

where $\mathrm{U}$ is the velocity vector representing the three directions $\mathrm{x}, \mathrm{y}$ and $\mathrm{z}$.

\subsubsection{Modelling the oxygen concentration}

In an actual bioreactor air bubbles are sparged at the bottom of the reactor. As the bubbles travel from the bottom to the top, some of the oxygen is transported from the bubbles to the liquid phase. Simultaneously, some of the oxygen in the liquid phase is used by the cells. The concentration of oxygen in the liquid phase therefore depends on the transfer and uptake rates of oxygen. The simulations in this work are one-phase simulations, i.e. only the liquid phase was considered and the bubbles were not simulated. The oxygen profile in the gas phase is imposed, and used to derive the transport of oxygen to the liquid phase. The liquid oxygen profile is a function of liquid convection, transport from the gas-phase and the consumption of oxygen. The mass balance for the oxygen in the liquid phase was formulated as:

$$
\frac{\partial C_{O_{2}}}{\partial t}+\nabla\left(C_{O_{2}} U\right)+\left(q_{O_{2}}^{t}-q_{O_{2}}\right)=0
$$


where the oxygen uptake rate is described by:

$$
q_{O_{2}}=\frac{Y_{s o}}{Y_{s x}} \mu \cdot C_{x}
$$

and the oxygen transfer rate is described by:

$$
q_{O_{2}}^{t}=k_{L} a\left(\frac{y_{O_{2}}(H) \cdot P(H)}{H_{A}}-C_{O_{2}}\right)
$$

where $k_{l} a$ is a mass transfer coefficient, $y_{O_{2}}$ is the oxygen fraction, $P$ is the pressure, $\mathrm{H}$ is the height of the reactor and $H_{A}$ is the Henry's constant $(790.6 \mathrm{~atm} \cdot \mathrm{L} / \mathrm{mol}$ ).

It has been shown that the partial pressure of oxygen in the local gas phase varies with the position in the reactor $[20,21]$. The pressure was here defined as a function of the hydrostatic pressure. Therefore, the oxygen fraction $y_{\mathrm{O}_{2}}$ was defined to depend on the liquid height and decreased when the height approached the maximum liquid height of $10.5 \mathrm{~m}$. The oxygen fraction was defined to begin at 0.21 at the bottom of the reactor and was assumed to decrease with a logarithm average value between top and bottom of the reactor, which is illustrated in Figure 2. The slope of the function was obtained by using the model from Sieblist et al. [22]. This assumption was made to simulate that the partial pressure of the oxygen in the local gas phase actually decreased the longer the gas phase was present in the reactor. The assumption only applies if the microorganisms consumes some of the dissolved oxygen present in the reactor. The oxygen driving force was therefore not constant in the reactor, but depended on the height of the reactor. Furthermore, a constant $k_{L} a$ of $500 h^{-1}$ was assumed for all simulations as Morchain et al .[11]. $k_{L} a$ is assumed constant in the entire domain and independent of gas velocity, pressure and height. A constant $k_{L} a$ in the entire volume suggests an even distribution of the dissipated power by the impeller over the volume. This might not be the case in reality, but the assumption was made to simplify the simulations. 


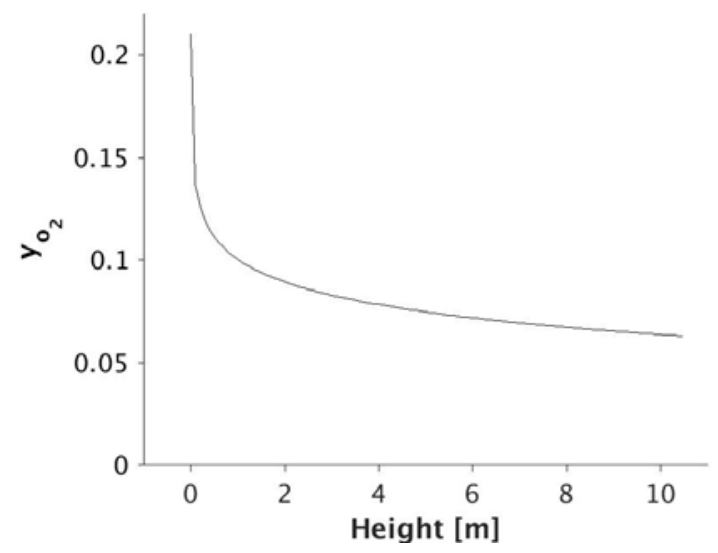

Figure 2: Oxygen fraction $y_{O_{2}}$ as a function of the height of the reactor. The slope of the function was obtained from Oosterhuis et al. [21].

\subsubsection{Metabolic shift}

To simulate the shift between the different metabolic states, $K_{s}, Y_{s x}$ and $\mu_{m a x}$ were set to depend on the glucose and oxygen concentrations. Aerobic and overflow metabolism were defined to take place when the oxygen concentration was above $0.42 \mathrm{mg} / \mathrm{L}$, corresponding to $5 \%$ of the saturation concentration of oxygen at normal pressure. The anaerobic metabolic shift is based on an assumption because experimentel data was not available. The scope of this study is to assess the sensitivity to uncertainty of kinetic models in CFD simulations, and the absolute value of the shift is not essential to this assessment. Therefore a suitable value was chosen. 


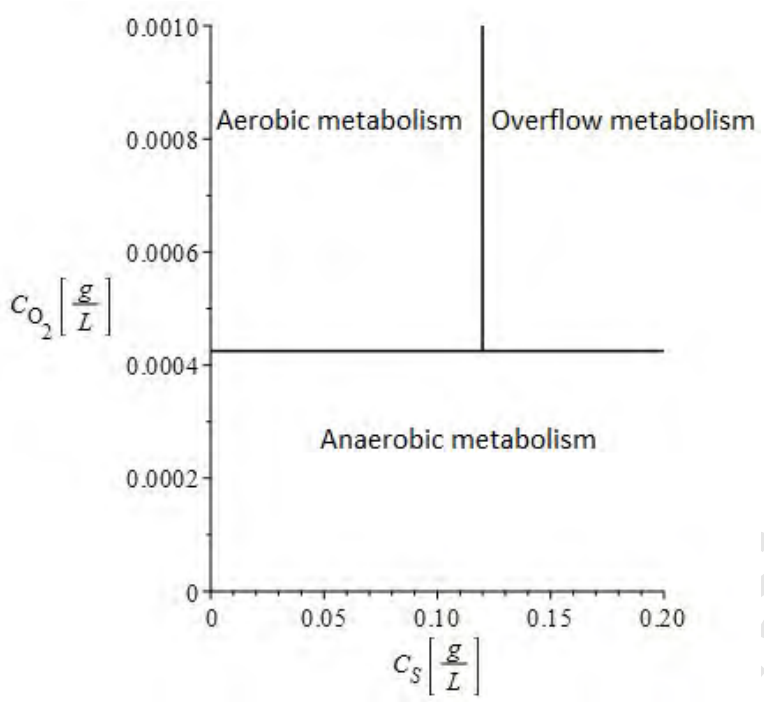

Figure 3: Boundaries between aerobic metabolism, overflow metabolism, and anaerobic metabolism defined in the kinetic model of $S$. cerevisiae.

The shift between aerobic metabolism and overflow metabolism was defined to take place for a glucose concentration of $0.12 \mathrm{~g} / \mathrm{L}[12]$. The shift between different metabolic states was assumed to be instantaneous and is illustrated in Figure 3. The assumption is based on Chassagnole et al. [23] who have shown that cells can switch metabolism in a matter of seconds. The kinetic parameters and their uncertainties corresponding to the different metabolic states can be seen in Table 2 . 
Table 2: Parameters and their uncertainties used for the simulation.

\begin{tabular}{llllr}
\hline Parameter & Value & Description & Unit & Reference \\
\hline$K_{s 1}$ & $0.02 \pm 0.002$ & Saturation for aerobic metabolism & $\mathrm{g} / \mathrm{L}$ & {$[12]$} \\
$K_{s 2}$ & $0.07 \pm 0.005$ & Saturation for overflow metabolism & $\mathrm{g} / \mathrm{L}$ & {$[12]$} \\
$K_{s 3}$ & $0.1 \pm 0.025$ & Saturation for anaerobic metabolism & $\mathrm{g} / \mathrm{L}$ & {$[24]$} \\
$Y_{s x 1}$ & $0.51 \pm 0.025$ & Yield coefficient for aerobic metabolism & $\mathrm{g} / \mathrm{g}$ & {$[12]$} \\
$Y_{s x 2}$ & $0.16 \pm 0.02$ & Yield coefficient for overflow metabolism & $\mathrm{g} / \mathrm{g}$ & {$[12]$} \\
$Y_{s x 3}$ & $0.086 \pm 0.02$ & Yield coefficient for anaerobic metabolism & $\mathrm{g} / \mathrm{g}$ & {$[24]$} \\
$\mu_{\max 1}$ & $0.49 \pm 0.01$ & Maximum growth rate for aerobic metabolism & $\mathrm{h}-1$ & {$[12]$} \\
$\mu_{\max 3}$ & $0.31 \pm 0.01$ & Maximum growth rate for anaerobic metabolism & $\mathrm{h}-1$ & {$[24]$} \\
$Y_{s o}$ & 0.04 & Oxygen yield coefficient & $\mathrm{g} / \mathrm{g}$ & {$[25]$} \\
$k_{L} a$ & 500 & Volumetric mass transfer coefficient & $\mathrm{h}^{-1}$ & Assumed \\
$H_{A}$ & 790.6 & Henry's constant & $\mathrm{atm} \cdot L / m o l$ & {$[26]$} \\
\hline
\end{tabular}

\subsection{Initial sensitivity study}

Simulations at the maximum reactor volume $\left(100 \mathrm{~m}^{3}\right)$ were carried out to investigate the sensitivity of the model prediction to variations in the kinetic constants. Kinetic data obtained from S. cerevisiae strain CBS8066 were used [12,24]. The saturation constant, yield coefficient and maximum growth rate were varied according to the uncertainty of the parameters shown in Table 2. Glucose was fed from the top at four different feed rates: $0.5 \mathrm{~kg} / \mathrm{s}, 1.0 \mathrm{~kg} / \mathrm{s}, 1.5$ $\mathrm{kg} / \mathrm{s}$ and $2.0 \mathrm{~kg} / \mathrm{s}$. The cell concentration was assumed to be $20 \mathrm{~g} / \mathrm{L}$ and constant throughout the entire reactor.

The size of the glucose gradients was detected by calculation of the ratio between the maximum and average glucose concentrations $\left(C_{\text {smax }} / C_{\text {save }}\right)$. Furthermore, the sensitivity of the glucose gradients to the varying kinetics was evaluated by:

$$
\frac{\left(\mathbf{C}_{\text {s max }} / \mathbf{C}_{\text {s ave }}\right)_{\text {deviation }}}{\left(\mathbf{C}_{\mathrm{s} \max } / C_{\text {s ave }}\right)_{\text {base case }}}
$$

Equation 10 describes how much the glucose gradient deviates from the base case.

$\left(\mathbf{C}_{\mathbf{s} \max } / \mathbf{C}_{\mathbf{s} \text { ave }}\right)_{\text {deviation }}$ is defined as the ratio between the maximum and average glucose concentrations for simulations where one of the kinetic parameters was varied with its as- 
signed uncertainty. The base case is defined as the simulations performed with the kinetic parameters shown in Table 2 without considering any uncertainties. The average glucose concentration was calculated by calculation of the glucose concentration in each hexahedral mesh element and then taking the average of calculated concentrations considering the volume of each hexahedral element.

\subsection{Fed-batch operation}

A fed-batch process was designed to investigate how the varying kinetics affect a full production cycle. The feeding profile was designed to keep the specific growth rate constant at 0.1 $h^{-1}$ under the assumption that the reactor is perfectly mixed. The feed rate at the different stages is shown in Table 3. The fed-batch process was simulated as steady-state for four different volumes to give four snapshots of the fed-batch process as it progressed. The fed-batch process was assumed to start at a cell concentration of $0.15 \mathrm{~g} / \mathrm{L}$. The specific growth rate was estimated for each volume and used to calculate the cell concentration for the subsequent step of the fed-batch process. The cell concentration at the subsequent step was calculated under the assumption that the cells grow under aerobic conditions and with the estimated specific growth rate.

Table 3: Feed rates at different times and volumes of the fed-batch process.

\begin{tabular}{ccc}
\cline { 2 - 3 } Time $[h]$ & Volume $\left[\mathrm{m}^{3}\right]$ & Feed rate $[\mathrm{g} / \mathrm{s}]$ \\
\hline 0 & 25 & 0.2 \\
34 & 30 & 5.6 \\
54 & 50 & 46.7 \\
66 & 100 & 148.4 \\
\hline
\end{tabular}

\section{Results and discussion}

\subsection{Gradients in the reactor}

CFD simulations were performed to investigate the glucose and oxygen distribution in the reactor. Both the glucose and oxygen concentration depend on their position in the reactor. 
The highest glucose concentration was found near the feed point located in the upper right corner of the reactor, which can be seen in Figure 4a. Moreover, more than half of the reactor (the bottom half) was predicted to have glucose concentrations below $1 \mathrm{mg} / \mathrm{L}$. The predictions of the glucose concentration were in the same order of magnitude as the prediction made by Larsson et al. [3], who measured a glucose concentration between $0.08 \mathrm{~g} / \mathrm{L}$ and $1 \mathrm{mg} / \mathrm{L}$ in a 30 $m^{3}$ reactor. Therefore, it can be concluded that the cells at the bottom of the reactor would grow under starvation conditions, which might have a negative effect on the performance of the reactor.

Glucose $[\mathrm{g} / \mathrm{L}]$
0.200
0.175
0.150
0.125
0.101
0.076
0.051
0.026
0.001

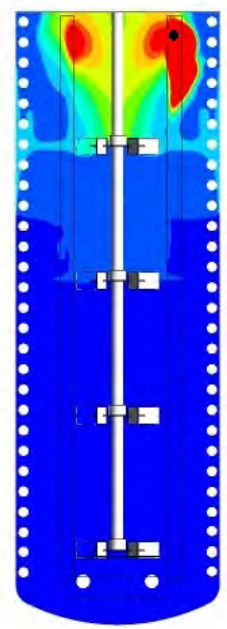

(a)

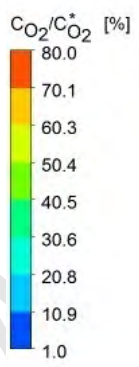

(b)

Figure 4: Glucose concentration (4a) and the ratio between the oxygen and the oxygen saturation concentration at normal pressure (4b) when the reactor volume is $100 \mathbf{m}^{3} . F=0.15 \mathrm{~kg} / \mathrm{s}, K_{s 1}=$ $0.02 \mathrm{~g} / \mathrm{L}, K_{s 2}=0.07 \mathrm{~g} / \mathrm{L}, K_{s 3}=0.1 \mathrm{~g} / \mathrm{L}, Y_{s x 1}=0.51 \mathrm{~g} / \mathrm{g}, Y_{s x 2}=0.16 \mathrm{~g} / \mathrm{g}$, and $Y_{s x 3}=0.086 \mathrm{~g} / \mathrm{g}$. The oxygen concentration was defined as the ratio between the oxygen concentration and the saturation concentration at normal pressure. The source point for dosing glucose is located in the top right corner indicated with a black dot. The mixing time is $678 \mathrm{~s}$.

The oxygen concentration varied along the height of the reactor. The highest oxygen concentration was found at the bottom of the reactor and the lowest at the top of the reactor. This is inverse of the glucose concentration which suggests the existence of regions with anaerobic growth. The lowest oxygen concentration is found close to the source point, where the glucose concentration and therefore the oxygen uptake is highest. 


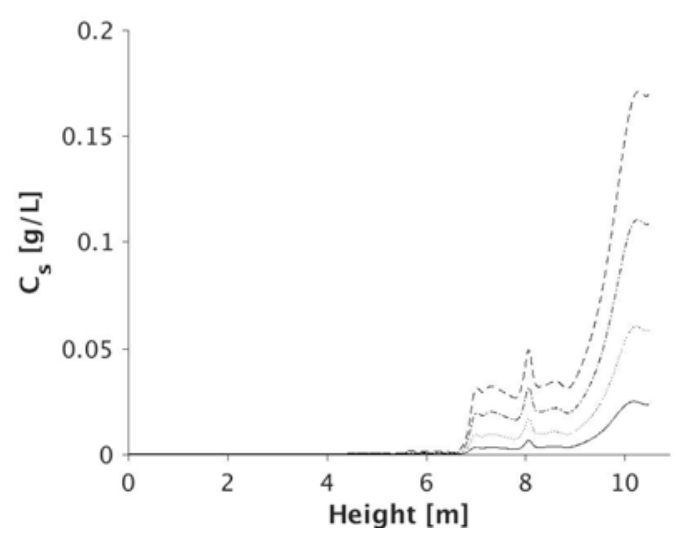

(a) Glucose concentration.

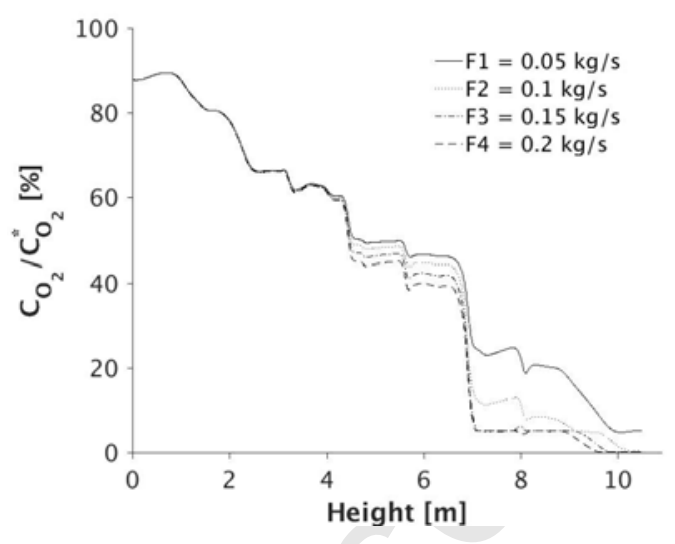

(b) Oxygen concentration.

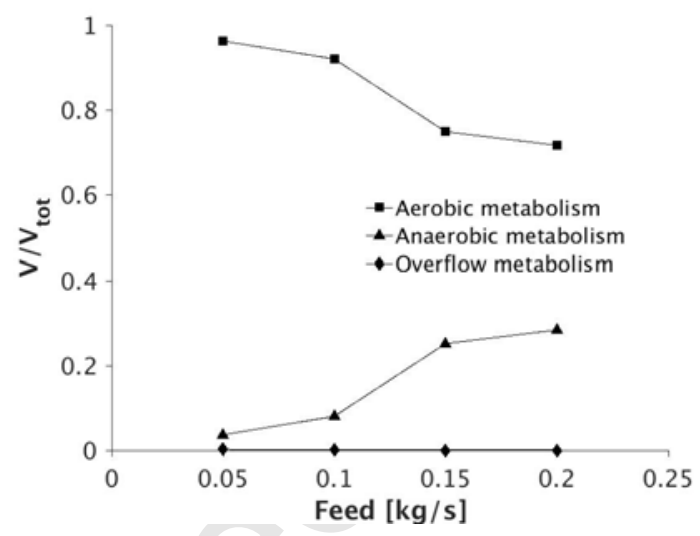

(c)

Figure 5: Glucose concentration (5a) and oxygen concentration (5b) at different feed rates as a function of the reactor height and the volume fraction with the different metabolism states as a function of the feed rate (5c) when the reactor volume is $100 \mathrm{~m}^{3} \cdot K_{s 1}=0.02 \mathrm{~g} / L, K_{s 2}=0.07 \mathrm{~g} / L$, $K_{s 3}=0.1 \mathrm{~g} / L, Y_{s x 1}=0.51 \mathrm{~g} / \mathrm{g}, Y_{s x 2}=0.16 \mathrm{~g} / \mathrm{g}$, and $Y_{s x 3}=0.086 \mathrm{~g} / \mathrm{g}$

Both the glucose concentration and the oxygen concentration depended on the feed rate, which can be seen in Figures 5a and 5b. The figures show the glucose and oxygen concentration as function of the reactor height. The concentrations were estimated at a straight line drawn from the bottom to the top of the reactor. It can be seen that as the feed rate increased, the glucose concentration at the top of the reactor increased. For all four feed rates, low glucose concentrations below $1 \mathrm{mg} / \mathrm{L}$ were found in the bottom six meters of the reactor.

The oxygen concentration also depended on the feed rate. As seen in Figure 5b, the oxygen concentrations were almost identical and independent of the feed rate in the first 4 meters of 
the reactor. At the top of the reactor, the oxygen concentration decreased as the feed rate increased. This indicates that a considerable part of the oxygen uptake rate takes place at the top of the reactor where plenty of glucose is present.

The low oxygen concentration at the top of the reactor resulted in an increased volume fraction with anaerobic metabolism and a decreased volume fraction with aerobic metabolism as observed in Figure 5c. The Figure shows the simulated volume fraction of the metabolic stages as a function of the feed rate. At a low feed rate of $0.05 \mathrm{~kg} / \mathrm{s}$, almost the entire reactor operated under aerobic metabolism. The volume fraction with anaerobic metabolism increased as the feed rate increased due to the higher glucose concentration at the top of the reactor for a higher feed rate. As the oxygen uptake rate depends on the glucose concentration, the oxygen concentration decreased as the glucose concentration increased.

The investigated conditions did not give rise to a region with overflow metabolism, because of the low glucose feeding and insufficient oxygen transfer. A higher feed rate should be employed along with a higher oxygen transfer rate (OTR) to see overflow metabolism.

\subsection{Effects of varying kinetics}

To investigate the robustness of the model, the kinetics were varied with the uncertainty related to the kinetic parameters, found in the literature (see Table 2). The robustness of the model was evaluated by calculation of the deviation from the base case scenario of the ratio between the maximum and average glucose concentration (see Section 2.5 for further description). The model was evaluated with the four feed flow rates, which can be seen in Figure 6.

The anaerobic kinetics had the largest effect on the glucose gradients. Both the yield coefficient and the saturation constant affected the ratio with more than $5 \%$ at all feed rates and the effect on the ratio increased as the feed rate increased. The highest difference was found for the yield coefficient, which increased from a difference in the ratio of $10 \%$ at a feed rate of $0.05 \mathrm{~kg} / \mathrm{s}$ to a difference of $25 \%$ at a feed rate of $0.2 \mathrm{~kg} / \mathrm{s}$.

The kinetic parameters for aerobic metabolism were all found to affect the ratio between the maximum and average glucose concentration with $2 \%$ to $5 \%$ at all feed rates. The difference decreased as the feed flow increased, due to the smaller volume fraction of the reactor with 


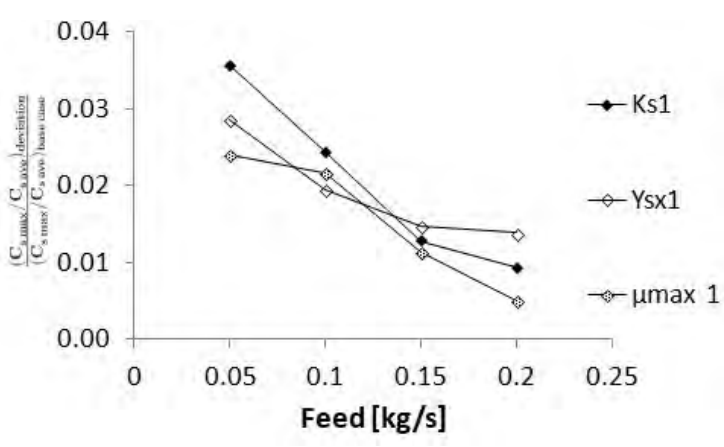

(a)

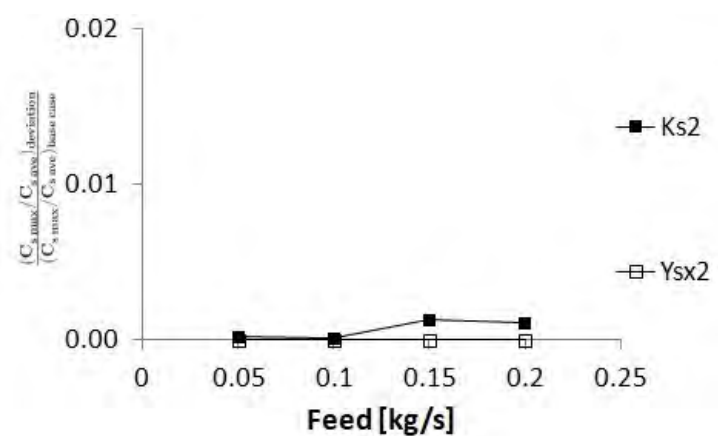

(b)

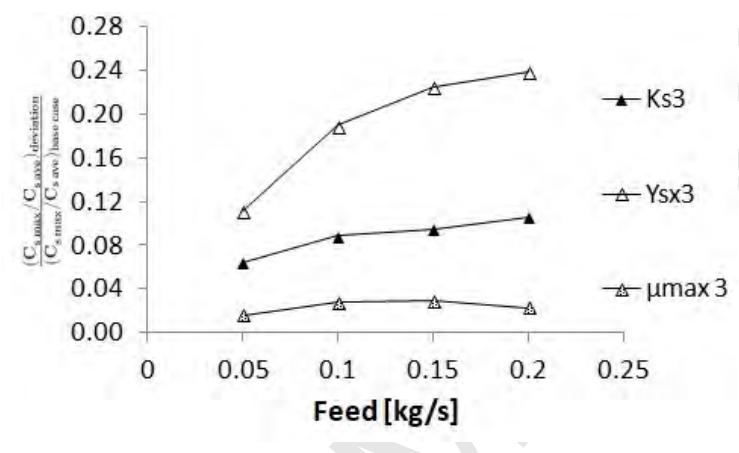

(c)

Figure 6: The deviation from the base case scenario of the ratio between the maximum and the average glucose concentration as a function of the feed rate. Each line represents the deviation from the base case caused by the uncertainty of the parameter. The volume of the reactor is $100 \mathrm{~m}^{3} .1$ represents parameters describing aerobic metabolism (6b), 2 represents parameters related to overflow metabolism (6c) and 3 represents parameters related to anaerobic metabolism (6a).

aerobic metabolism found at higher feed rates.

The CFD model showed no sensitivity towards the kinetic parameters associated with overflow metabolism as shown in Figure 6. This is a result of the reactor operating at a lower concentration of glucose throughout the reactor. Furthermore, the lack of oxygen in the top part of the reactor prevents overflow metabolism to occur even though the glucose concentration is high enough. The effect of varying kinetics related to overflow metabolism will therefore not be further investigated in this work, because of the low impact at the investigated conditions. The larger influence of the anaerobic parameters on the glucose concentration could be explained by the higher uncertainty of the anaerobic parameters compared to the aerobic parameters reported in the literature, which is illustrated in Table 4. For instance, the deviation 
of $25 \%$ for the glucose distribution caused by $Y_{s x 3}$ more or less corresponds to the uncertainty of $23 \%$ for this parameter. Moreover, the influence of anaerobic parameters on the glucose concentration increased as the feed rate increased. This can be explained by the increase in the reactor volume fraction with anaerobic metabolism as the feed rate increased. Furthermore, Table 4 shows that the variation caused by the yield coefficient and specific growth rate is more or less equal to the uncertainty of the parameters. For the saturation constants the maximum deviation from the base case is less than half of the uncertainty of the same parameter. The uncertainty of the parameters for the saturation constants therefore has a smaller influence compared with the other parameters.

Table 4: The kinetic parameters and their uncertainties in percent together with the maximum deviation from the base case observed in Figure 6.

\begin{tabular}{l|ccc|ccc|cc}
\hline Parameter & $K_{s 1}$ & $K_{s 2}$ & $K_{s 3}$ & $Y_{s x 1}$ & $Y_{s x 2}$ & $Y_{s x 3}$ & $\mu_{\max 1}$ & $\mu_{\max 3}$ \\
Uncertainty [\%] & 10 & 7 & 25 & 5 & 13 & 23 & 2 & 3 \\
Max observed $\frac{\left(\mathbf{C}_{\mathbf{s} \max } / \mathbf{C}_{\mathbf{s} \text { ave }}\right)_{\text {deviation }}}{\left(\mathbf{C}_{\mathbf{s} \max } / C_{\mathbf{s} \text { ave }}\right)_{\text {base case }}}$ & 4 & 0.1 & 11 & 3 & 0 & 25 & 2 & 3 \\
\hline
\end{tabular}

\subsection{Fed-batch process}

A fed-batch process was designed to investigate how the uncertain growth kinetics affect the operation at different degrees of filling in the process. The fed-batch was designed so the specific growth rate was kept constant at $0.1 h^{-1}$. The rotational speed was kept constant at $69 \mathrm{rpm}$ for all volumes. The initial volume was defined to be $25 \mathrm{~m}^{3}$ and the final volume to be $100 \mathrm{~m}^{3}$. The determination of the power input and the mixing time can be seen in the supplementary material. An illustration of the four simulated volumes is shown in Figure 7. 

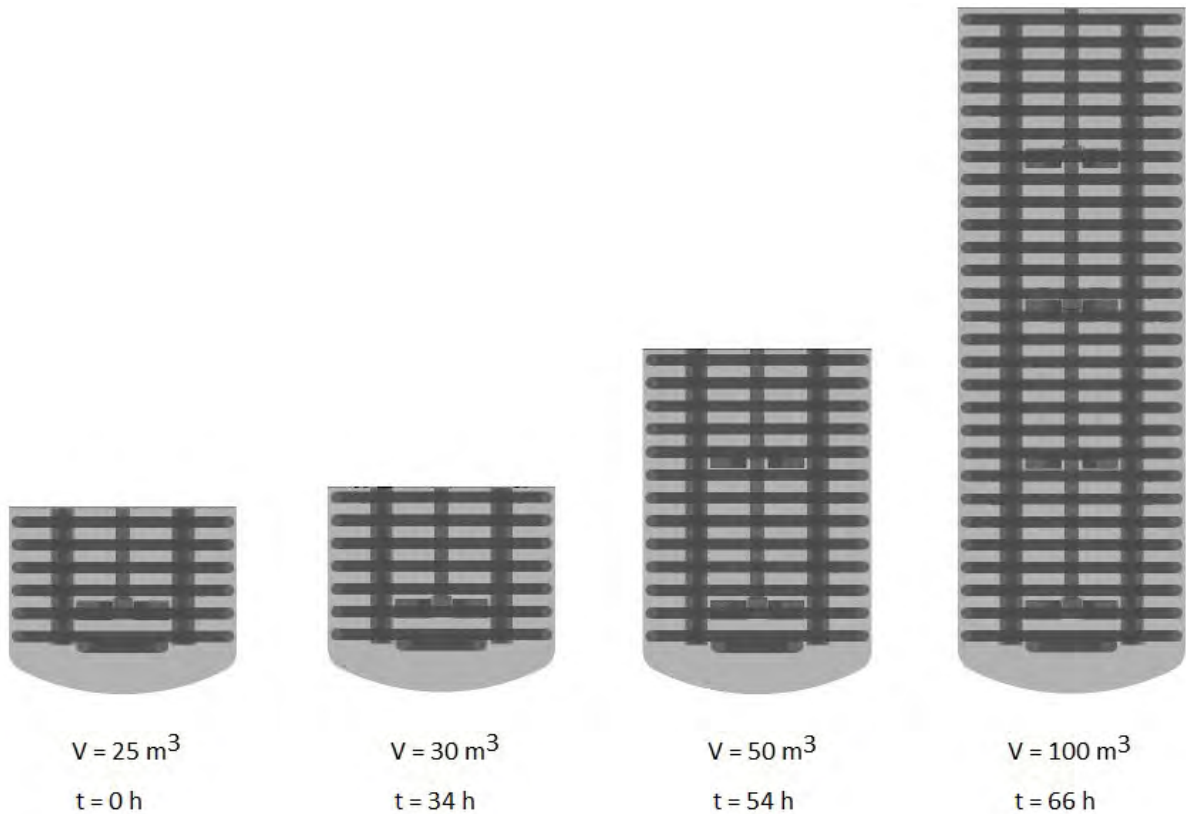

$V=30 \mathrm{~m}^{3}$

$V=50 \mathrm{~m}^{3}$

$\mathrm{V}=100 \mathrm{~m}^{3}$

$\mathrm{t}=34 \mathrm{~h}$

$\mathrm{t}=54 \mathrm{~h}$

$\mathrm{t}=66 \mathrm{~h}$

Figure 7: Illustration of the four volumes used for the simulation of different stages in the fed-batch operation of the bioreactor.

The power input for all four volumes was found to be between $1.2 \mathrm{~kW} / \mathrm{m}^{3}$ and $1.4 \mathrm{~kW} / \mathrm{m}^{3}$ (Figure 8a). Furthermore, the mixing time increased from $20 \mathrm{~s}$ at $25 \mathrm{~m}^{3}$ to almost $700 \mathrm{~s}$ at $100 \mathrm{~m}^{3}$. As expected, the larger volume resulted in less effective mixing. The mixing times obtained here were considered to be reasonable as Vrabel et al. [27] have achieved mixing times of $140-250$ seconds for a $30 \mathrm{~m}^{3}$ reactor with a power input of $0.3-2.0 \mathrm{~kW} / \mathrm{m}^{3}$.

The less effective mixing for larger volumes affected the formation of gradients in the reactor. The ratio between the maximum and the average glucose concentration increased from close to 1 in the initial volume to 2400 in the final volume, meaning that the glucose gradients increased significantly the longer a fed-batch process was operated (Figure 8b). At the initial volume, the ratio between the maximum and average glucose concentration was close to 1 and therefore almost no glucose gradients were found. The lack of glucose gradients can be explained by the low cell concentration of $0.15 \mathrm{~g} / \mathrm{L}$ in the start-up phase, which resulted in a low glucose consumption rate. Furthermore, a relatively good mixing is found at this point of the fed-batch process.

The sensitivity of the glucose concentration also depends on the volume and operation time (Figure 8c). For all cases, the deviation increased from the initial volume to the second 


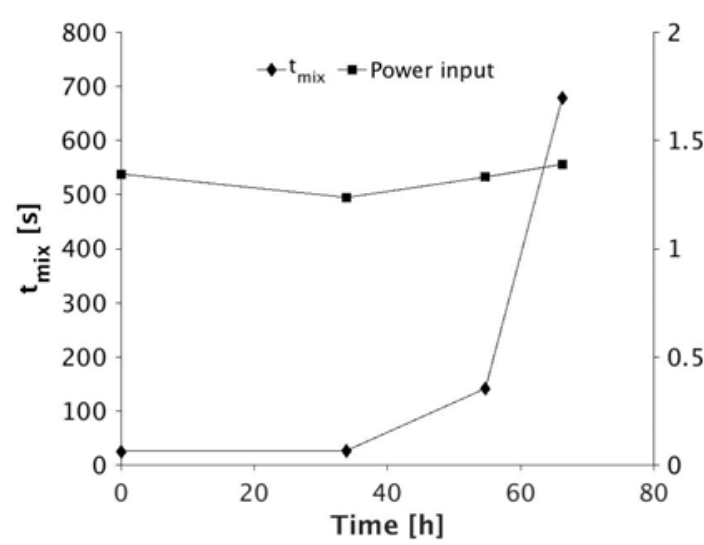

(a)

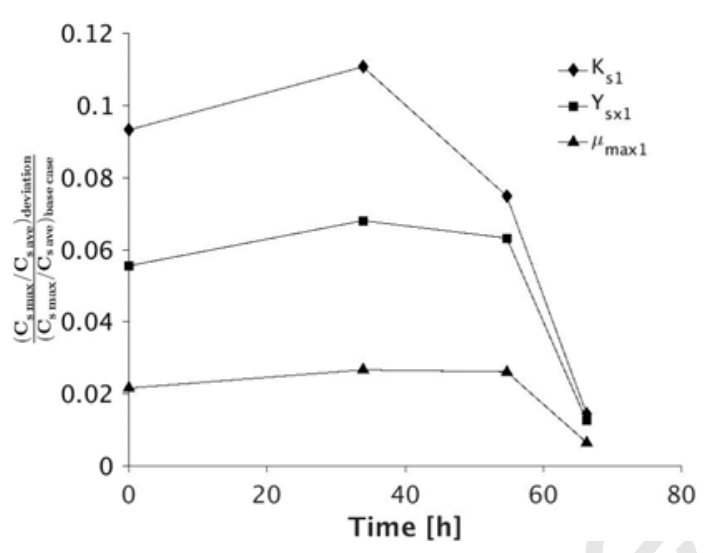

(c)

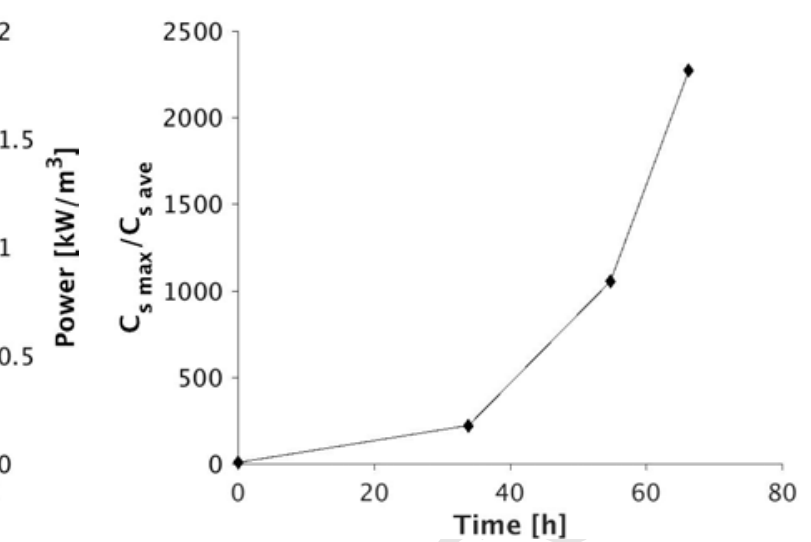

(b)

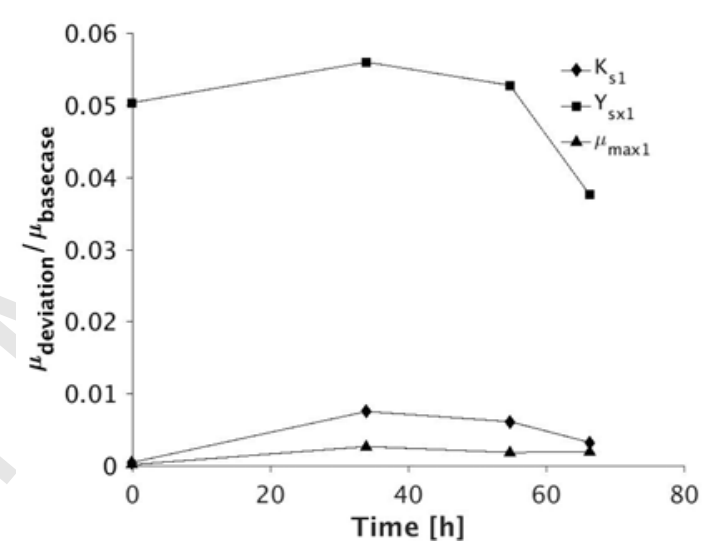

(d)

Figure 8: Prediction of mixing time and power input (8a), the ratio between the maximum and average glucose concentration for the base case $(8 \mathrm{~b})$, the deviation from the base case of the ratio between the maximum and average glucose concentration (8c) and the deviation of the specific growth rate from the base case (8d) all as a function of time. Each time step corresponds to a different volume of the reactor operating as a fed-batch. Each line in Figures 8c and $8 \mathrm{~d}$ represents the deviation from the base case caused by the uncertainty of the parameter. Moreover, only the effect of parameters describing the aerobic metabolic stage are shown.

volume, then it decreased subsequently. In the final volume, the observed difference was around $1 \%$ for all cases. An explanation for this could be that almost no glucose is present in a large part of the reactor caused by a high mixing time (678 seconds) and a high glucose consumption rate. The saturation constant was found to have the largest effect on the glucose concentration. The saturation concentration and the maximum specific growth rate had little effect on the specific growth rate (Figure $8 \mathrm{~d}$ ), where only deviations of maximum $1 \%$ from 
the base case were observed for all volumes. The yield showed a larger effect on the specific growth rate, with a deviation between $4 \%$ and $5 \%$ from the base case.

The yield coefficient does not directly affect the specific growth rate (Equation 4). It only has an indirect influence on the specific growth rate by affecting the glucose concentration. In contrast to both the maximum specific growth rate and the saturation constant which both affected the specific growth rate and the glucose concentration. These two effects seemed to counteract each other. Therefore, less deviations in the specific growth rate were observed compared to the yield coefficient.

In order to investigate how the deviation in the yield coefficient affects the formation of cells, a simulation of the reactor at different volumes of the fed-batch operation was made with varying yield coefficients. The cell concentration increased exponentially and ended at approximately $20 \mathrm{~g} / \mathrm{L}$ in the final volume, which can be seen in Figure 9a. The specific growth rate was calculated for each volume and used to calculate the subsequent cell concentration. The deviation in the yield coefficient had only a minor effect on the formation of the cells. The cell development for $Y_{s x}=0.485$ and $Y_{s x}=0.535$ oscillated around the base case, but seemed to end at almost the same cell concentration.

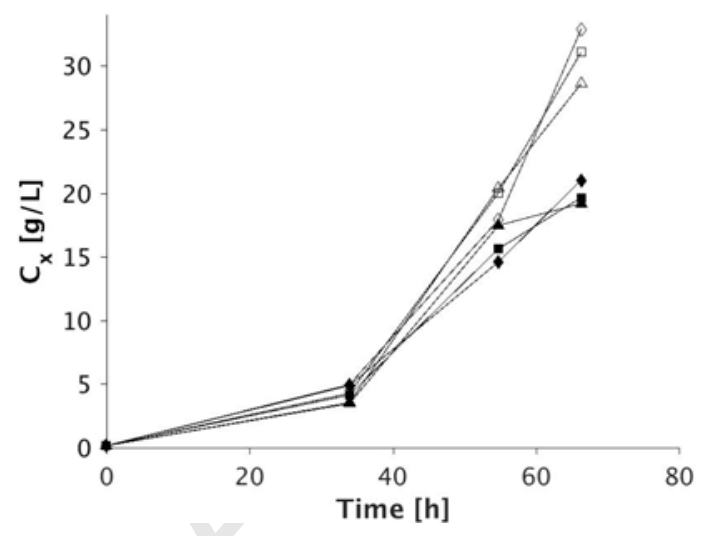

(a)

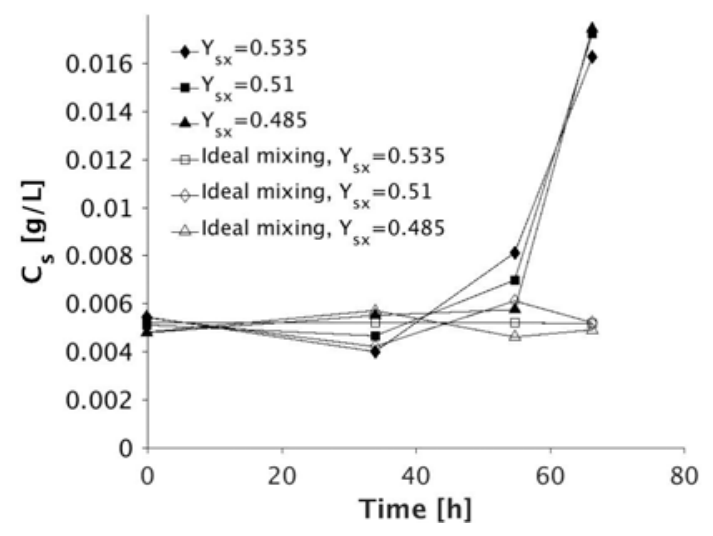

(b)

Figure 9: Simulation of the reactor operating as a fed-batch with varying $Y_{s x 1}$. Cell concentration (9a) and glucose concentration $(9 \mathrm{~b})$ as a function of time.

The feeding profile was designed to obtain a specific growth rate of $0.1 h^{-1}$, when $Y_{s x}=0.51$. The higher yield coefficient resulted in a higher cell concentration for the subsequent volume. Then the cell concentration was too high to match the feeding profile, and the average glucose 
concentration would therefore be lower compared to the base case. This can be observed in Figure 9b, where the glucose concentration as a function of time is depicted.

In the first and second simulated volume of the fed-batch operation, the average glucose concentration was almost the same at approximately $0.005 \mathrm{~g} / \mathrm{L}$. However, in the last two simulations, the glucose concentration increased, meaning that the cell development was too low compared to the feeding profile. This was confirmed by simulations where ideal mixing was assumed. The deviation in the yield coefficient affected the cell development, but only small deviations were observed. The final cell concentration was approximately $30 \mathrm{~g} / \mathrm{L}$ when ideal mixing was assumed. Moreover, the glucose concentration was more or less constant at $5 \mathrm{mg} / \mathrm{L}$. The difference of biomass concentration between CFD simulation and simulation of perfect mixing conditions was $10 \mathrm{~g} / \mathrm{L}$ or $33 \%$ at the final volume. The deviation between the CFD simulation and the ideal mixing simulation is caused by the inability to predict anaerobic growth in the ideal mixing case, since conditions in the reactor are homogeneous due to the ideal mixing assumption. In reality the feed rate will be adjusted to avoid or minimize areas with anaerobic metabolism, i.e. feed rate will be adjusted based on a dissolved oxygen measurement in order to keep aerobic conditions in the reactor.

The results presented in this work are not a perfect description of the reality. Several assumptions were made to simplify the simulations. For instance, only the liquid phase was simulated, but an industrial bioreactor would contain both a gas phase and a liquid phase. Furthermore, the oxygen fraction in the gas phase $\left(y_{\mathrm{O}_{2}}\right)$ was assumed to decrease exponentially between the bottom and top of the reactor, which is illustrated in Figure 2. The assumed oxygen fraction might have a major influence on the oxygen profile shown in this manuscript. In reality the oxygen fraction in the gas phase and the transport from the gas to the liquid phase depends on many factors, such as bubble size, oxygen concentration in the liquid phase and oxygen consumption by the cells. Therefore the oxygen profile shown in this manuscript is not a perfect description of the reality. To achieve more realistic results, the gas phase should be included. By including the gas phase, both mixing of the reactor and the oxygen concentration should be affected. The sensitivity of the kinetic parameters is however expected to be more or less the same, as the kinetic parameters used in this work do not depend on the oxygen profile. Only the size of the volume fractions with the different metabolism depends on the oxygen profile. To achieve more realistic results, the gas phase should be included but this will add 
considerable complexity to the simulations. There are major contradictions in the literature how the gas phase affect the mixing. Boualifi et al. [28] found that the mixing time increased as the gas flow increased. However Shewale et al. [29] got contrary results.

A uniform cell population was assumed for all the microorganisms in the entire reactor, i.e.

no differences between the individual cells. In reality, S. cerevisiae is a living organism with a cell life cycle. Different levels of physiological activities with different physiological states have been reported for cells living in the same culture [30, 31]. A population balance could be introduced to account for this. The challenges with population balances is that they are quite complicated, and this will therefore complicate the simulations even more [32, 33]. A population balance introduces several new parameters with different uncertainties, which also have to be investigated to secure the robustness of the simulations.

Besides describing the formation of gradients in an industrial bioreactor at different volumes of a fed-batch operation, the presented work provides another tool for optimization of an industrial bioreactor. The simulations could be used to identify the performance of the reactor if microorganisms are improved by strain improvements. If biomass production is the purpose, an obvious target for strain improvement could be the yield coefficient $Y_{s x 1}$. A higher yield coefficient is expected to result in a higher cell concentration. This would be predicted by simulations where ideal mixing is assumed. In reality this might not be the case. For instance, the increased yield coefficient might result in a larger reactor volume with anaerobic conditions. In the end it might result in slower growing cells and/or a less efficient process, which could cause a lower productivity. The effect of such phenomena can be evaluated by using CFD together with kinetics, which gives valuable insight into the benefits of certain strain improvements.

\section{Conclusion}

In this work, the robustness of a CFD-based model, used to describe the growth of S. cerevisiae in a $100 \mathrm{~m}^{3}$ bioreactor, was tested by varying the kinetic constants with the uncertainties reported in the literature. The model describing the growth consisted of the metabolic stages: aerobic, overflow and anaerobic. The kinetic parameters were evaluated at four different feed flow rates: $0.05 \mathrm{~kg} / \mathrm{s}, 0.1 \mathrm{~kg} / \mathrm{s}, 0.15 \mathrm{~kg} / \mathrm{s}$ and $0.2 \mathrm{~kg} / \mathrm{s}$. The cells were found to primarily 
grow under aerobic conditions, but also areas with anaerobic metabolism were observed. The area with anaerobic metabolism increased as the feed flow rate increased. The uncertainty of kinetic parameters describing aerobic metabolism affected the glucose concentration with $2 \%$ to $5 \%$ at all flow rates. The largest deviation of the glucose concentration was found to be $25 \%$ when simulating the effect of uncertain parameters of the anaerobic metabolism.

A fed-batch process was designed to investigate the sensitivity of the parameters for an operating reactor. The sensitivity was investigated at four different volumes of the reactor. The degree of glucose gradient was found to increase as the fed-batch process proceeds, due to the increased volume and higher mixing time. The sensitivity of the model compared to the base case was largest in the beginning of the process. The saturation constant had the largest impact on the glucose concentration and the yield coefficient had the largest impact on the specific growth rate. Therefore the development of the cell concentration caused by the varying yield coefficient was investigated. Small deviations in the cell concentration were found at the final volume. But by comparing the CFD simulation with a simulation where ideal mixing was assumed, a deviation in the biomass concentration of approximately $10 \mathrm{~g} / \mathrm{L}$ or $33 \%$ was found in the final volume. Therefore, it can be concluded that the CFD simulations give opportunities, which cannot be achieved with simulations where ideal mixing is assumed. Moreover, the CFD simulations presented in this work have shown a way to investigate the effect, caused by a change in a kinetic parameters on a bioreactor operating as a fed-batch. The derived CFD model can be a tool to evaluate the effect of strain improvements on reactor performance.

\section{Acknowledgements}

This project has received funding from the Technical University of Denmark (DTU) and Innovation Fund Denmark in the frame of the Strategic Research Center BIOPRO2 (BIObased Production: Towards the next generation of optimized and sustainable processes). 


\section{References}

[1] S. Ostergaard, L. Olsson, and J. Nielsen, "Metabolic Engineering of Saccharomyces cerevisiae," Microbiology and Molecular Biology Reviews, vol. 64, no. 1, pp. 34-50, 2000.

[2] F. Bylund, E. Collet, S. O. Enfors, and G. Larsson, "Substrate gradient formation in the large-scale bioreactor lowers cell yield and increases by-product formation," Bioprocess Engineering, vol. 18, no. 3, pp. 171-180, 1998.

[3] G. Larsson, M. Törnkvist, E. Ståhl Wernersson, C. Trägårdh, H. Noorman, and S. O. Enfors, "Substrate gradients in bioreactors: Origin and consequences," Bioprocess Engineering, vol. 14, no. 6, pp. 281-289, 1996.

[4] A. R. Khopkar and P. A. Tanguy, "CFD simulation of gas-liquid flows in stirred vessel equipped with dual rushton turbines: influence of parallel, merging and diverging flow configurations," Chemical Engineering Science, vol. 63, no. 14, pp. 3810-3820, 2008.

[5] M. Taghavi, R. Zadghaffari, J. Moghaddas, and Y. Moghaddas, "Experimental and CFD investigation of power consumption in a dual Rushton turbine stirred tank," Chemical Engineering Research and Design, vol. 89, no. 3, pp. 280-290, 2011.

[6] C. Bach, J. Yang, H. Larsson, S. M. Stocks, K. V. Gernaey, M. O. Albaek, and U. Krühne, "Evaluation of mixing and mass transfer in a stirred pilot scale bioreactor utilizing CFD," Chemical Engineering Science, vol. 171, pp. 19-26, 2017.

[7] J. Wutz, A. Lapin, F. Siebler, J. E. Schäfer, T. Wucherpfennig, M. Berger, and R. Takors, "Predictability of kLa in stirred tank reactors under multiple operating conditions using an Euler-Lagrange approach," Engineering in Life Sciences, vol. 16, no. 7, pp. 633-642, 2016.

[8] C. Haringa, W. Tang, A. T. Deshmukh, J. Xia, M. Reuss, J. J. Heijnen, R. F. Mudde, and H. J. Noorman, "Euler-Lagrange computational fluid dynamics for (bio)reactor scale down: An analysis of organism lifelines," Engineering in Life Sciences, vol. 16, no. 7, pp. 652-663, 2016. 
[9] A. Lapin, J. Schmid, and M. Reuss, "Modeling the dynamics of E. coli populations in the three-dimensional turbulent field of a stirred-tank bioreactor-A structured-segregated approach," Chemical Engineering Science, vol. 61, no. 14, pp. 4783-4797, 2006.

[10] M. Elqotbi, S. D. Vlaev, L. Montastruc, and I. Nikov, "CFD modelling of two-phase stirred bioreaction systems by segregated solution of the Euler-Euler model," Computers and Chemical Engineering, vol. 48, pp. 113-120, 2013.

[11] J. Morchain, J.-C. Gabelle, and A. Cockx, "A Coupled Population Balance Model and CFD Approach for the Simulation of Mixing Issues in Lab-Scale and Industrial Bioreactors," Wiley Online Library, 2013.

[12] E. Postma, W. Alexander Scheffers, and J. P. Van Dijken, "Kinetics of Growth and Glucose Transport in Glucose-limited Chemostat Cultures of Saccharomyces cerevisiae CBS 8066," Yeast, vol. 5, no. 3, pp. 159-165, 1989.

[13] L. K. Ju and G. G. Chase, "Improved scale-up strategies of bioreactors," Bioprocess Engineering, vol. 8, no. 1, pp. 49-53, 1992.

[14] M. Linkès, M. Martins Afonso, P. Fede, J. Ô. Morchain, and P. Schmitz, "Numerical study of substrate assimilation by a microorganism exposed to fluctuating concentration," Chemical Engineering Science, vol. 81, pp. 8-19, 2012.

[15] D. D. McClure, J. M. Kavanagh, D. F. Fletcher, and G. W. Barton, "Characterizing bubble column bioreactor performance using computational fluid dynamics," Chemical Engineering Science, vol. 144, pp. 58-74, apr 2016.

[16] P. Stanbury, Principles of fermentation technology. Oxford, U.K. Tarrytown, N.Y., U.S.A: Pergamon, 1995.

[17] K. K. Hong and J. Nielsen, "Metabolic engineering of Saccharomyces cerevisiae: A key cell factory platform for future biorefineries," Cellular and Molecular Life Sciences, vol. 69, no. 16 , pp. 2671-2690, 2012.

[18] D. D. R. H., "The Crabtree Effect: A Regulatory System in Yeast," Journal of General Microbiology, vol. 44, no. 2, pp. 149-156, 1966. 
[19] P. V. Hoek, J. P. V. Dijken, and J. T. Pronk, "Effect of Specific Growth Rate on Fermentative Capacity of Baker 's Yeast," vol. 64, no. 11, pp. 4226-4233, 1998.

[20] H. Noorman, B. Hjertager, K. Morud, C. Träigådh, C. Enfors, S.-O, and M. Larsson, G.; Törnkvist, "Measurement and computational fluid dynamics simulation of Saccharomyces cerevisiae production in a $30 \mathrm{~m} 3$ stirred reactor," Proc. Bioreactor Performance Symp., Helsingør Denmark, ed. Mortensen, Noorman, The Biotechnology Research Foundation, 1993.

[21] N. M. Oosterhuis and N. W. Kossen, "Dissolved oxygen concentration profiles in a production-scale bioreactor.," Biotechnology and bioengineering, vol. 26, no. 5, pp. 546550, 1984.

[22] C. Sieblist, O. Hägeholz, M. Aehle, M. Jenzsch, M. Pohlscheidt, and A. Lübbert, "Insights into large-scale cell-culture reactors: II. Gas-phase mixing and CO 2 stripping," Biotechnology Journal, vol. 6, no. 12, pp. 1547-1556, 2011.

[23] K. Chassagnole, C. , Noisommit-Rizzi, N. , Schmid, J. W., Mauch and Reuss, "Dynamic modeling of the central carbon metabolism of Escherichia coli," Biotechnol. Bioeng., 79: 53-73, 2002.

[24] C. Verduyn, E. Postma, W. A. Scheffers, and J. P. van Dijken, "Physiology of Saccharomyces Cerevisiae in Anaerobic Glucose-Limited Chemostat Cultures," Journal of General Microbiology, vol. 136, no. 3, pp. 395-403, 1990.

[25] R. A. Weusthuis, W. Visser, J. T. Pronk, W. A. Scheffers, and J. P. Van Dijken, "Effects of oxygen limitation on sugar metabolism in yeasts: A continuous-culture study of the Kluyver effect," Microbiology, vol. 140, no. 4, pp. 703-715, 1994.

[26] J. Villadsen, Nielsen, and G. Liden, Bioreaction Engineering Principles. 3rd. ed., 2011.

[27] P. Vrabel, R. G. J. M. Van Der Lans, K. C. A. M. Luyben, L. Boon, and A. W. Nienow, "Mixing in large-scale vessels stirred with multiple radial or radial and axial up-pumping impellers: Modelling and measurements," Chemical Engineering Science, vol. 55, no. 23, pp. 5881-5896, 2000. 
[28] M. Bouaifi and M. Roustan, "Power consumption, mixing time and homogenisation energy in dual-impeller agitated gas-liquid reactors," Chemical Engineering and Processing: Process Intensification, vol. 40, pp. 87-95, feb 2001.

[29] S. D. Shewale and A. B. Pandit, "Studies in multiple impeller agitated gas-liquid contactors," Chemical Engineering Science, vol. 61, pp. 489-504, jan 2006.

[30] C. Hatzis, F. Srienc, and A. G. Fredrickson, "Feeding heterogeneity in ciliate populations: Effects of culture age and nutritional state," Biotechnology and Bioengineering, vol. 43, no. 5, pp. 371-380, 1994.

[31] D. P. LAVIN, C. HATZIS, F. SRIENC, and H. A. G. FREDRICKSON, "Size Effects on the Uptake of Particles by Populations of Tetrahymena pyriformis Cells," vol. J. Prolozo, 1990.

[32] R. L. Fernandes, M. Carlquist, L. Lundin, A. L. Heins, A. Dutta, S. J. Sørensen, A. D. Jensen, I. Nopens, A. E. Lantz, and K. V. Gernaey, "Cell mass and cell cycle dynamics of an asynchronous budding yeast population: Experimental observations, flow cytometry data analysis, and multi-scale modeling," Biotechnology and Bioengineering, vol. 110, no. 3, pp. 812-826, 2013.

[33] J. J. Liou, F. Srienc, and A. G. Fredrickson, "Solutions of population balance models based on a successive generations approach," Chemical Engineering Science, vol. 52, no. 9, pp. 1529-1540, 1997.

\section{Nomenclature}




\begin{tabular}{|c|c|c|}
\hline Symbol & Name & Unit \\
\hline$C_{i}$ & Concentration of component $i$ & $\mathrm{~kg} / \mathrm{m}^{3}$ \\
\hline$H_{A}$ & Henry's constant & atm $\cdot L / m o l$ \\
\hline$H$ & Liquid height & $\mathrm{m}$ \\
\hline$K_{s}$ & Saturation constant for glucose & $\mathrm{kg} / \mathrm{m}^{3}$ \\
\hline$k_{L} a$ & Oxygen mass transfer coefficient & $\mathrm{h}^{-1}$ \\
\hline$P$ & Pressure & $\mathrm{Pa}$ \\
\hline$q_{i}$ & Volumetic uptake rate for compound $i$ & $\mathrm{~kg} /\left(\mathrm{m}^{3} \cdot h\right)$ \\
\hline$q_{\mathrm{O}_{2}}^{t}$ & Oxygen transfer rate & $\mathrm{kg} /\left(\mathrm{m}^{3} \cdot h\right)$ \\
\hline$S_{M}$ & Momentum source & $\mathrm{kg} \cdot \mathrm{m} / \mathrm{s}$ \\
\hline$t_{m i x}$ & Mixing time & {$[\mathrm{s}]$} \\
\hline$U$ & Velocity vector & $\mathrm{m} / \mathrm{s}$ \\
\hline$V$ & Volume & $\mathrm{m}^{3}$ \\
\hline$X$ & Cell concentration $i$ & $\mathrm{~kg} / \mathrm{m}^{3}$ \\
\hline$Y_{j i}$ & Yield coefficient of component $i$ on $j$ & $\mathrm{~g} / \mathrm{g}$ \\
\hline$y_{o_{2}}$ & Oxygen fraction in the gas bubbles & - \\
\hline$\rho$ & Density & $\mathrm{kg} / \mathrm{m}^{3}$ \\
\hline$\tau$ & Torque & $\mathrm{N}$ \\
\hline$\mu$ & Specific growth rate & $\mathrm{h}^{-1}$ \\
\hline$\mu_{\max }$ & Maximum growth rate & $h^{-1}$ \\
\hline
\end{tabular}

